\title{
Biphasic effects of zeranol on the growth of estrogen receptor-positive human breast carcinoma cells
}

\author{
TAKASHI YURI, REIKO TSUKAMOTO, KATSUAKI MIKI, NORIHISA UEHARA, \\ YOICHIRO MATSUOKA and AIRO TSUBURA
}

\author{
Department of Pathology II, Kansai Medical University, Moriguchi, Osaka 570-8506, Japan
}

Received May 2, 2006; Accepted August 7, 2006

\begin{abstract}
Zeranol ( $\alpha$-zearalanol) is a metabolite of the mycoestrogen zearalenone, and is used as a growth promoter of livestock due to its strong estrogenic activity. In the present study, we investigated the effects of zeranol on the growth of estrogen receptor (ER)-positive and -negative human breast carcinoma cells in vitro, and the molecules involved. At low concentrations, zeranol accelerated the growth of ER-positive MCF-7 and KPL-1 human breast carcinoma cells, but did not affect the growth of ER-negative MDA-MB-231 cells. At high concentrations, zeranol suppressed the growth of both ERpositive and -negative human breast carcinoma cells. The acceleration of ER-positive cell growth by low-dose zeranol involved the down-regulation of p21 ${ }^{\text {Cip } 1}$ (a cyclin-dependent kinase inhibitor), which resulted in cell cycle progression. High-dose zeranol induced the formation of a sub-G1 fraction and the up-regulation of the apoptosis stimulator p53, suggesting the induction of apoptosis. Thus, zeranol exerted dose-dependent biphasic effects on ER-positive human breast carcinoma cells, accelerating cell growth at low concentrations and inducing apoptosis at high concentrations.
\end{abstract}

\section{Introduction}

Epidemiological evidence regarding human breast cancer indicates that environmental factors play important roles in the etiology of this disease. Diet is considered one of the main risk factors of breast cancer, and the ingestion of estrogenic substances has been found to markedly affect breast cancer risk $(1,2)$. Zeranol ( $\alpha$-zearalanol [6-6,10-dihydroxyundecy1-ß-resorcylic acid lactone]) is a nonsteroidal molecule with estrogenic activity (Fig. 1). Zeranol is used as an anabolic growth promoter of livestock in the US and other countries. However, the use of zeranol as an anabolic growth promoter is prohibited in many other countries, including all member states of the EU $(3,4)$. The maximum safe daily

Correspondence to: Dr Airo Tsubura, Department of Pathology II, Kansai Medical University, Moriguchi, Osaka 570-8506, Japan

E-mail: tsubura@takii.kmu.ac.jp

Key words: apoptosis, human breast carcinoma cell, cell cycle, estrogen receptor, zeranol intake of zeranol is generally considered to be $0.16 \mathrm{mg} / \mathrm{day}$, and the tolerance level for tissue residue of zeranol has been calculated as $315 \mathrm{ppb}$ (3). Zeranol is a natural metabolite of zearalenone, which is a mycoestrogen synthesized by Fusarium molds. Zeranol is present as a natural contaminant in food as a result of grain infection by Fusarium molds (5). Thus, humans may ingest zeranol via meat products from livestock that has been treated with zeranol or fed moldinfected grains, or via Fusarium-contaminated grains. Zeranol and zearalenone bind to the estrogen receptors (ERs), and zeranol has greater estrogenic potency than zearalenone $(4,6)$. Zeranol acts as an estrogenic substance in estrogen target organs, and it can have strong endocrine-disrupting effects. When zeranol is administered to female SpragueDawley rats or CD-1 mice at a prepubertal stage (when they have low endogenous estrogen levels), it causes phenomena such as early vaginal opening and estrous cycle irregularity $(7,8)$. In rats, zeranol has been found to cause morphological changes such as anovulatory ovaries (ovaries without newly formed corpora lutea) (7).

Estrogen plays a pivotal role in the development of the mammary gland and in the genesis of breast cancer. Estrogen has been found to promote the growth of estrogen-dependent breast cancer cells via the regulation of cell cycle progression (9). In contrast, increasing evidence indicates that estrogen can induce apoptosis of breast cancer cells; i.e., negative regulation of cell growth by estrogen (10). The phytoestrogens genistein (11) and resveratrol (12) have been shown to have antiproliferative effects on human breast carcinoma cells in vitro via cell cycle arrest and apoptosis. Exposure of prepubertal female rats to zeranol tends to suppress the development of $\mathrm{N}$-methyl-N-nitrosourea-induced mammary carcinomas in those rats (7). However, there have been no reports concerning the precise effects of zeranol on human breast cancer cell growth in vitro. Therefore, in the present study, we investigated the growth-modulating effects of zeranol on ER-positive MCF-7 and KPL-1 human breast carcinoma cells in vitro, to clarify the molecular mechanisms of cell growth alterations in relation to cell cycle transition and apoptosis. For comparison, we also examined the effects of zeranol on ERnegative MDA-MB-231 human breast carcinoma cells.

\section{Materials and methods}

Reagents. Zeranol and $17 ß$-estradiol were purchased from Wako Pure Chemical (Osaka, Japan). The purity of the zeranol 


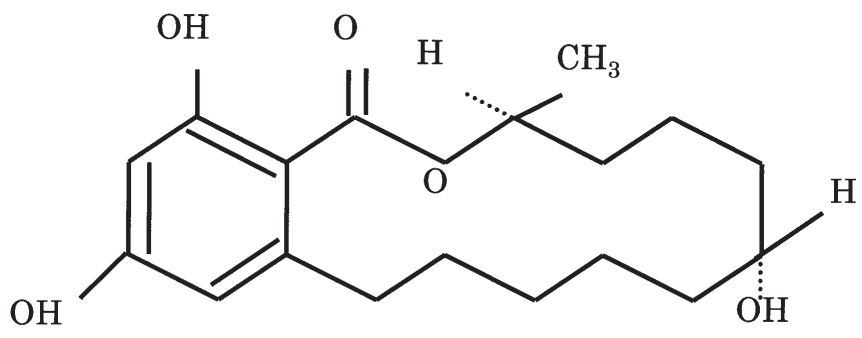

Figure 1. The chemical structure of zeranol ( $\alpha$-zearalanol).

and $17 ß$-estradiol was $99 \%$ and $>97 \%$, as determined by high-performance liquid chromatography and absorptiometry, respectively. Monoclonal antibodies against p21 ${ }^{\text {Cip1 }}$ (SX-118) and $\mathrm{p} 27^{\mathrm{Kip} 1}$ (57) were obtained from BD Transduction (Lexington, KY, USA). The monoclonal antibody against p53 (DO-7) was obtained from DakoCytomation (Glostrup, Denmark). Polyclonal antibodies against cyclin E (M-20) were obtained from Santa Cruz Biotechnology (Santa Cruz, CA, USA). Polyclonal antibodies against Bcl-2 and Bak were obtained from from BD Transduction. Polyclonal antibodies against actin were obtained from Sigma (St. Louis, MO, USA).

Cell lines and culture conditions. MCF-7 (13) and KPL-1 (14) are human breast carcinoma cell lines that are ERpositive and estrogen-dependent. MDA-MB-231 is a human breast cancer cell line that is ER-negative (15). All cell lines were cultured in phenol-red-free Dulbecco's modified Eagle's minimum essential medium (DMEM D5921; Sigma) containing $10 \%$ dextran-charcoaled estrogen-stripped fetal calf serum (FCS) (Thermo Electrone, Thebarton, Australia) and $0.5 \mathrm{~g} / \mathrm{l}$ glutamin (Nissui, Tokyo, Japan), in $5 \% \mathrm{CO}_{2} / 95 \%$ humidified air at $37^{\circ} \mathrm{C}$.

Cell proliferation assay. The effects of zeranol on human breast cancer cell growth were determined using a colorimetric 3-(4,5-dimethylthiazol-2-yl)-2,5-diphenyltetrazolium bromide (MTT) assay as described previously (16). Briefly, the cells were seeded in 96 -well plates at $2 \times 10^{3}$ cells per well. After the cells adhered to the bottom of the plates, 1 of 7 different concentrations of zeranol $(0.5 \mathrm{nM}$ to $500 \mu \mathrm{M})$ dissolved in dimethylsulfoxide (DMSO; Nacalai Tesque, Kyoto, Japan) was added to each well. After 72-h incubation with the zeranol, MTT (Sigma) was added to each well. The final concentration of DMSO in the culture medium was $<0.1 \%$, and had no antiproliferative effect on the cells. Results were expressed as the percentage ratio of the number of viable cells after incubation with zeranol to the number of viable cells after incubation in the vehicle $(0.1 \%$ DMSO; control). Each datum was the mean value of 8 wells.

Cell cycle analysis. Cells were starved (incubated in FCSfree DMEM) for $24 \mathrm{~h}$ to synchronize their cell cycles. Then, the cells were incubated with $50 \mathrm{nM}$ zeranol, $50 \mu \mathrm{M}$ zeranol or the vehicle ( $0.1 \%$ DMSO; control), for the indicated times. The cells were then trypsinized, and floating cells were washed in cold phosphate-buffered saline (PBS) (-), centrifuged and fixed with $70 \%$ ethanol. The samples were then treated with RNase, diluted with PBS (-), stained with $50 \mu \mathrm{g} / \mathrm{ml}$ propidium

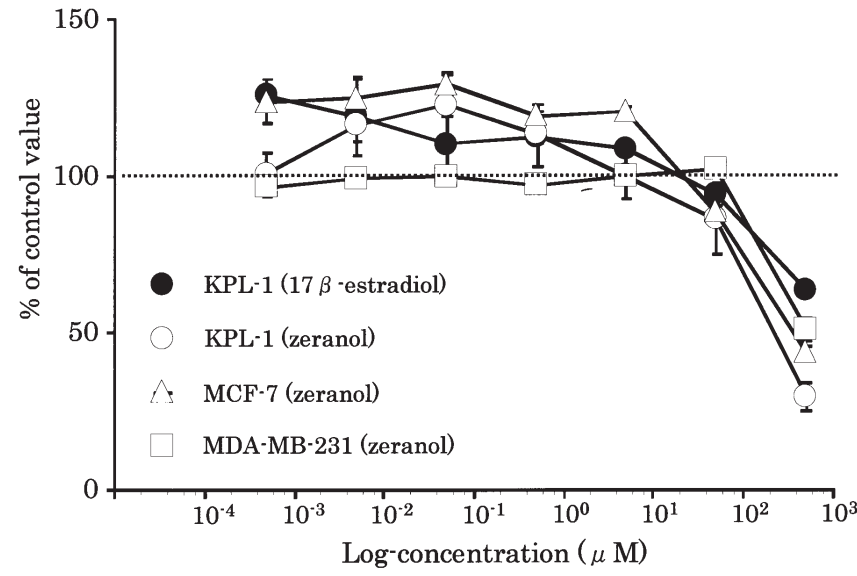

Figure 2. Dose-dependent growth modulation curves of estrogen receptorpositive and -negative human breast carcinoma cell lines after $72-\mathrm{h}$ incubation with zeranol or 17ß-estradiol.

iodide, and analyzed by FACScan flow cytometry (Beckton Dickinson, Mountain View, CA, USA). Cell cycle distribution was quantified using ModFit LT software (Verity Software House, Topsham, ME, USA). For the analysis, proper gating was used to exclude doublets and other cell aggregates.

Immunoblot analysis. Synchronized cells were incubated with $50 \mathrm{nM}$ zeranol, $50 \mu \mathrm{M}$ zeranol or the vehicle $(0.1 \%$ DMSO; control), for the indicated times. After washing with cold PBS (-), the cells were trypsinized and the cell pellets were lysed using lysis buffer [50 mM Tris- $\mathrm{HCl}$ (pH 6.8), $2 \%$ SDS, 5 mM B-mercaptoethanol, 10\% glycerol]. Cell lysates were clarified by centrifugation at $12,000 \mathrm{x} \mathrm{g}$ for $30 \mathrm{~min}$. Protein concentrations were analyzed by Bio-Rad assay (BioRad, Richmond, CA, USA). Cell lysates were electrophoresed on $15 \%$ SDS-PAGE gel (60 $\mu \mathrm{g}$ protein per lane), and were then electroblotted onto a transfer membrane (GeneScreen Plus, Perkin-Elmer Life Sciences, Boston, MA, USA). The membranes were blocked with 5\% dry milk in Tris buffered saline-Tween (TBST) for $1 \mathrm{~h}$ at room temperature. They were then incubated with antibodies against p21 ${ }^{\mathrm{Cip} 1}, \mathrm{p} 27^{\mathrm{Kip} 1}$, cyclin E, p53, Bcl-2 or Bak, at $4^{\circ} \mathrm{C}$ overnight. Next, the membranes were incubated with Dako Envision peroxidaseconjugated anti-mouse or anti-rabbit secondary antibody (DakoCytomation). The bands were visualized using an ECL chemiluminescent detection kit (Amersham Biosciences, Buckinghamshire, UK). The intensity of each band was calculated using Scion Image Software (Scion Corporation, Frederick, MD, USA).

Statistical analysis. All results are expressed as mean \pm SE. The significance of the differences was determined using the unpaired two-group t-test or the Mann-Whitney U test, after assuring homogeneity of variance. Differences with a probability value of $\mathrm{p}<0.05$ were considered significant.

\section{Results}

Effects of zeranol on the growth of ER-positive and-negative human breast carcinoma cell lines in vitro. At low concentrations $(<5 \mu \mathrm{M})$, zeranol and $17 ß$-estradiol significantly 


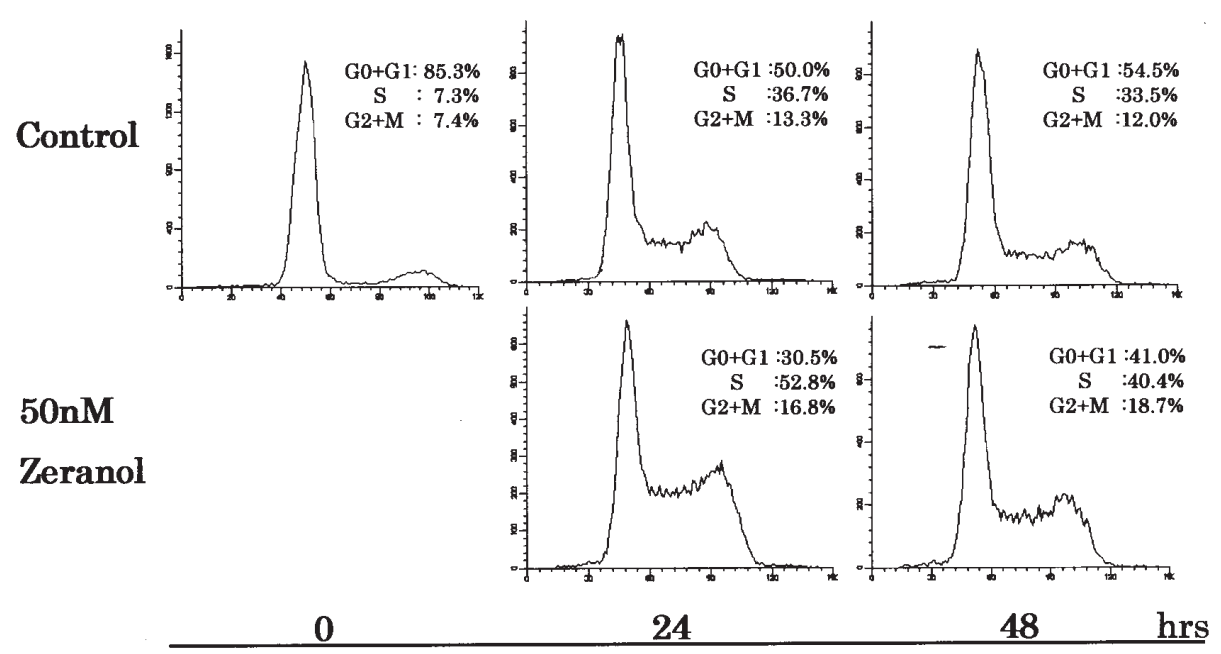

Figure 3. Flow cytometry. Low-dose (50 nM) zeranol accelerates the cell cycle progression of estrogen receptor-positive MCF-7 human breast carcinoma cells.

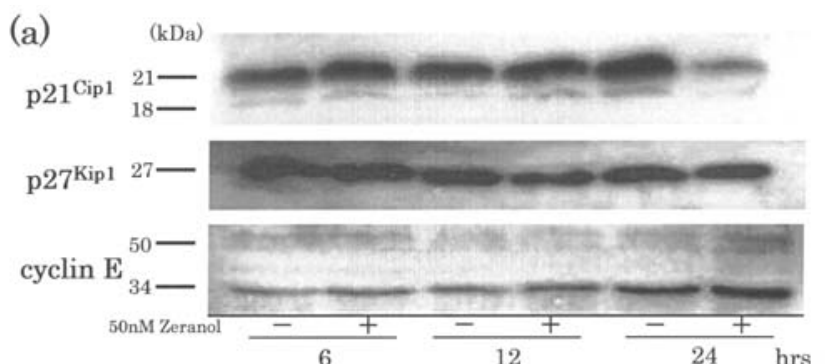

(b)

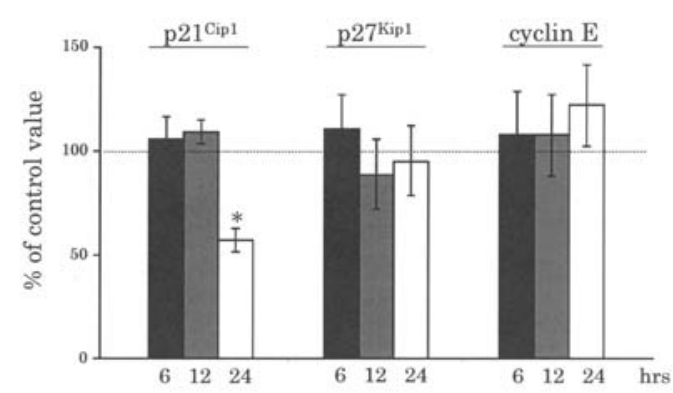

Figure 4. Western blotting. Representative results (a) and quantitative data (b) after 6-, 12- and 24-h exposure of MCF-7 cells to low-dose (50 nM) zeranol. After 24-h exposure to low-dose zeranol, the expression of the CDK inhibitor $\mathrm{p} 21^{\mathrm{Cip} 1}$ was significantly suppressed.

stimulated the growth of KPL-1 and MCF-7 cells, but did not stimulate the growth of MDA-MB-231 cells (Fig. 2). For both KPL-1 and MCF-7, the concentration of zeranol that produced the greatest proliferation of cells was $50 \mathrm{nM}$; at that concentration, MCF-7 proliferated at a greater rate than KPL-1. At high concentrations $(\geq 50 \mu \mathrm{M})$, zeranol dose-dependently significantly inhibited the cell proliferation of all 3 cell lines; KPL-1 cells exhibited the greatest degree of growth inhibition.

Acceleration of growth of MCF-7 human breast carcinoma cells by low-dose zeranol. MCF-7 cells were used to examine the molecular mechanisms of zeranol-induced growth acceleration, because MCF-7 cells proliferated at a greater rate in response to $50 \mathrm{nM}$ zeranol than did KPL-1 cells, as described in the preceding paragraph (Fig. 2). The incubation of synchronized MCF-7 cells with $50 \mathrm{nM}$ zeranol for $24 \mathrm{~h}$ significantly accelerated G1-to-S phase progression and significantly increased the percentage of cells in the $S$ phase, compared with vehicle-treated cells (Fig. 3). After incubation with $50 \mathrm{nM}$ zeranol for $48 \mathrm{~h}$, the percentage of cells in the G2/M phase was $6.7 \%$ greater than that of vehicle-treated cells. Representative Western blotting of MCF-7 cells is shown in Fig. 4a, and the corresponding quantitative data are shown in Fig. 4b. Incubation with $50 \mathrm{nM}$ zeranol decreased the expression of $\mathrm{G} 1 / \mathrm{S}$ cyclin-dependent kinase (CDK) inhibitors ( $\mathrm{p} 21^{\mathrm{Cip} 1}$ and $\mathrm{p} 27^{\mathrm{Kip} 1}$ ), and increased the expression of cyclin $\mathrm{E}$; the change in $\mathrm{p} 21^{\mathrm{Cip} 1}$ expression at $24 \mathrm{~h}$ was significant.

Suppression of growth of KPL-1 human breast carcinoma cells by high-dose zeranol. KPL-1 cells were used to examine the molecular mechanisms of zeranol-induced growth inhibition, because KPL-1 cells exhibited the greatest growth suppression after incubation with $50 \mu \mathrm{M}$ zeranol (Fig. 2). MDA-MD-231 cells, which did not exhibit growth suppression after incubation with $50 \mu \mathrm{M}$ zeranol, were included for comparison. After 96-h incubation with $50 \mu \mathrm{M}$ zeranol, KPL-1 cells exhibited apparent sub-G1 fractions, whereas MDA-MB-231 cells did not (Fig. 5). Representative Western blotting results and quantitative data for KPL-1 cells treated with $50 \mu \mathrm{M}$ zeranol are shown in Fig. $6 \mathrm{a}$ and b, respectively. After 72-h incubation with $50 \mu \mathrm{M}$ zeranol, the expression of the apoptotic cell death stimulator p53 was significantly upregulated, the expression of the apoptosis suppressor Bcl-2 was decreased (not significantly), and the expression of the apoptosis accelerator Bak was increased (not significantly).

\section{Discussion}

In the present study, zeranol (a mycoestrogen-related substance and a potent growth promoter for livestock) exerted biphasic effects on the growth of ER-positive human breast carcinoma cells in a dose-dependent manner. Zeranol stimulated the growth of ER-positive MCF-7 and KPL-1 human breast 
KPL-1

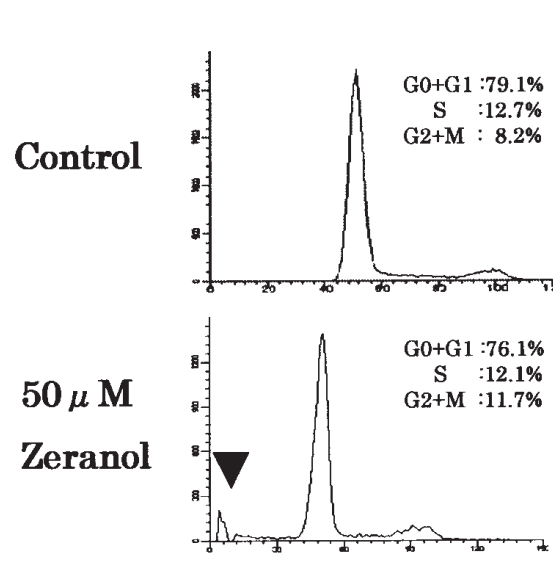

48

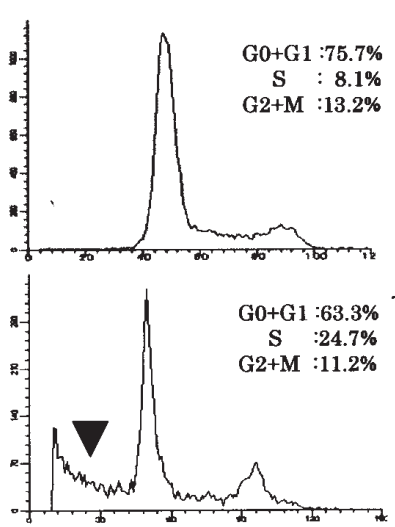

96
MDA-MB-231

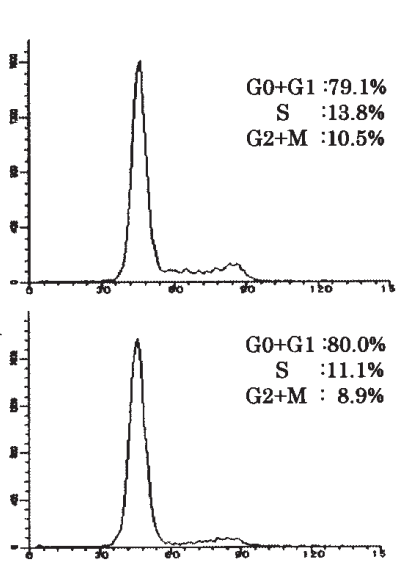

96

hrs

Figure 5. Flow cytometry. High-dose $(50 \mu \mathrm{M})$ zeranol induced the formation of a sub-G1 fraction among ER-positive KPL-1 cells, but not among ERnegative MDA-MB-231 human breast carcinoma cells. The arrowheads indicate the sub-G1 fraction.

(a)

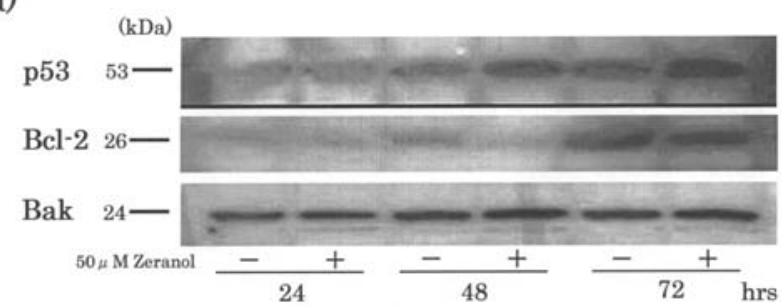

(b)

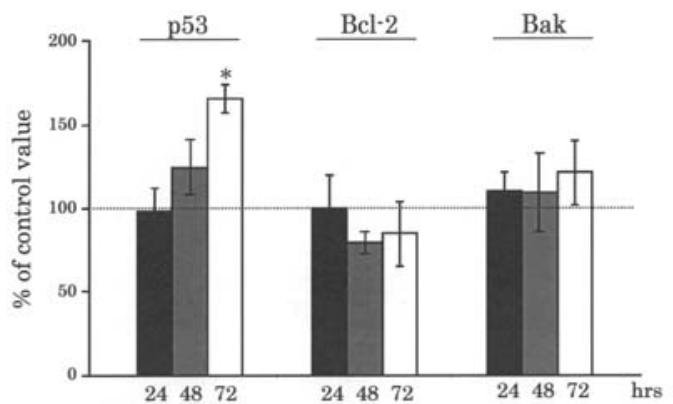

Figure 6. Western blotting. Representative results (a) and quantitative data (b) after 24-, 48- and 72-h exposure of KPL-1 cells to high-dose $(50 \mu \mathrm{M})$ zeranol. After 72-h exposure to high-dose zeranol, the expression of the apoptosis stimulator p53 was significantly increased, and the expression of $\mathrm{Bcl}-2$ and Bak (members of the Bcl-2 family of proteins) was altered, though not significantly.

carcinoma cells at low concentrations $(<5 \mu \mathrm{M})$, and inhibited the growth of MCF-7 and KPL-1 cells at high concentrations $(\geq 50 \mu \mathrm{M})$. Zeranol inhibited the growth of ER-negative MDA-MB-231 human breast cancer cells at high concentrations $(>50 \mu \mathrm{M})$, but did not stimulate the growth of MDAMB-231 cells at low concentrations. These results are consistent with previous studies in which genistein and resveratrol (natural phytoestrogens found in soy and grapes, respectively) were found to cause the proliferation of ERpositive human breast carcinoma cells at low concentrations, and to suppress the growth of ER-positive human breast carcinoma cells at high concentrations $(11,12)$.

The growth-stimulating effect of the phytoestrogens genistein and quercetin on ER-positive human breast carcinoma cells is ER $\alpha$-mediated (17). Zearalenone stimulates the growth of MCF-7 cells (18), HHUA human endometrial adenocarcinoma cells, SKN leiomyosarcoma cells, and HepG2 hepatoma cells; and this effect is abolished by the pretreatment of these cells with an ER blocker (19). Passage through the cell cycle is determined by the function of the cyclin/CDK complex $(20,21)$. Treatment of human breast carcinoma cells with $100 \mathrm{nM}$ zearalenone induces cell cycle progression, increases the expression of cyclins D1, A and $\mathrm{B} 1$, and down-regulates the CDK inhibitor p27 ${ }^{\mathrm{Kip} 1}$ (18). In the present study, $50 \mathrm{nM}$ zeranol significantly accelerated cell cycle progression, significantly suppressed $\mathrm{p} 21^{\mathrm{Cip} 1}$, and non-significantly increased cyclin E expression. p21 Cip/Waf1, a member of the Cip/Kip family, acts as a broad specific inhibitor of cyclins D, E and A (22). Long-term low-dose exposure to zeranol transforms MCF-10A human breast epithelial cells (23).

At high concentrations, the phytoestrogen genistein induces apoptosis and cell cycle arrest of hormone-dependent and -independent human breast cancer cell lines $(11,24)$ and a human gastric cancer cell line (25). Genistein causes cell cycle arrest at the G2/M phase, whereas the phytoestrogens daidzein and luteolin arrest the cell cycle at the G1 phase (25). The mycoestrogen zearalenone induces apoptotic cell death and G2/M arrest in human colon and tongue carcinoma cells (26). In the present study, zeranol induced apoptosis in both ER-positive and -negative human breast cancer cells, but there was no clear evidence of cell cycle arrest in those cells. Based on such findings, estrogen has been considered for possible clinical use in adjuvant chemotherapy for human breast carcinomas. Before the development of selective ER modulators (SERM), diethylstilbestrol (which has relatively strong estrogenic activity) was commonly used in chemotherapy for postmenopausal metastatic breast cancer patients 
(27). The apoptosis-inducing activity of estrogen is the major factor in its ability to reduce numbers of breast cancer cells (10). ER-positive mouse mammary carcinomas maintained by syngeneic transplantation have regressed completely after estrogen treatment (28). Estrogen has also been found to cause complete tumor regression of ER-positive human breast carcinomas transplanted into male nude mice (29). Moreover, estrogen inhibits the growth of raloxifene (a SERM)-resistant MCF-7 cells in vitro and in vivo (30).

The protein p53 plays an essential role in the apoptosis cascade of mammalian cells (31). In mouse mammary carcinomas, an elevated expression of p53 has been observed after estrogen treatment (28). In the present study, the upregulation of p53 correlated with the growth suppression of estrogen-dependent human breast carcinoma cells. The apoptosis cascade involves numerous molecules downstream from p53, including Bcl-2 and Bak (members of the Bcl-2 family of proteins). In the present study, the expression of Bcl-2 and Bak was altered (though not significantly) by apoptosis-inducing zeranol treatment. The apoptosisinducing properties of zeranol resemble those of phytoestrogens that have cytotoxic activity $(11,12)$. Although the precise mechanisms of the cytotoxic properties of estrogen and estrogenic substances are still somewhat unclear, the available evidence suggests that high-dose zeranol can strongly suppress cell growth in human breast cancer.

In conclusion, the present findings indicate that zeranol has dose-dependent effects on the cell growth of ER-positive human breast cancer: Low-dose zeranol stimulated cell growth by altering the cell cycle components; high-dose zeranol induced cell cycle block and apoptotic cell death. The present induction of cell cycle acceleration by low-dose zeranol was accompanied by the down-regulation of $\mathrm{p} 21^{\text {Cip } 1}$ (a G1/S CDK inhibitor). The present induction of apoptotic cell death by high-dose zeranol was mediated by the upregulation of the apoptosis stimulator $\mathrm{p} 53$, and may have involved members of the Bcl-2 family of proteins.

\section{Acknowledgements}

The authors wish to thank Ms. T. Akamatsu for her excellent technical assistance, and Ms. S. Nakagawa for typing the manuscript. This research was supported in part by the program Health and Labor Science Research on Risk of Chemical Substances, of the Ministry of Health, Labor and Welfare, Japan, and by a Grant-in-Aid for Scientific Research (C) from the Japan Society for the Promotion of Science (17591361).

\section{References}

1. Key TJ, Allen NE, Spencer EA and Travis RC: Nutrition and breast cancer. Breast 12: 412-416, 2003.

2. Tsubura A, Uehara N, Kiyozuka Y and Shikata N: Dietary factors modifying breast cancer risk and relation to time of intake. J Mammary Gland Biol Neoplasia 10: 87-100, 2005.

3. Baldwin RS, Williams RD and Terry MK: Zeranol: a review of the metabolism, toxicology, and analytical methods for detection of tissue residues. Regul Toxicol Pharmacol 3: 9-25, 1983.

4. Leffers H, Naesby M, Vendelbo B, Skakkebaek NE and Jorgensen M: Oestrogenic potencies of Zeranol, oestradiol, diethylstilboestrol, Bisphenol-A and genistein: implications for exposure assessment of potential endocrine disrupters. Hum Reprod 16: 1037-1045, 2001.
5. Olsen M, Pettersson $\mathrm{H}$ and Kiessling KH: Reduction of zearalenone to zearalenol in female rat liver by 3 alphahydroxysteroid dehydrogenase. Acta Pharmacol Toxicol 48: 157-161, 1981.

6. Le Guevel R and Pakdel F: Assessment of oestrogenic potency of chemicals used as growth promoter by in vitro methods. Hum Reprod 16: 1030-1036, 2001.

7. Yuri T, Nikaido Y, Shimano N, Uehara N, Shikata N and Tsubura A: Effects of prepubertal zeranol exposure on estrogen target organs and N-methyl-N-nitrosourea-induced mammary tumorigenesis in female Sprague-Dawley rats. In Vivo 18: 755-761, 2004.

8. Nikaido Y, Danbara N, Tsujita-Kyutoku M, Yuri T, Uehara N and Tsubura A: Effects of prepubertal exposure to xenoestrogen on development of estrogen target organs in female CD-1 mice. In Vivo 19: 487-494, 2005.

9. Doisneau-Sixou SF, Sergio CM, Carroll JS, Hui R, Musgrove EA and Sutherland RL: Estrogen and antiestrogen regulation of cell cycle progression in breast cancer cells. Endocr Relat Cancer 10: 179-186, 2003.

10. Song RX and Santen RJ: Apoptotic action of estrogen. Apoptosis 8: 55-60, 2003

11. Nakagawa H, Yamamoto D, Kiyozuka Y, Tsuta K, Uemura Y, Hioki K, Tsutsui $Y$ and Tsubura A: Effects of genistein and synergistic action in combination with eicosapentaenoic acid on the growth of breast cancer cell lines. J Cancer Res Clin Oncol 126: 448-454, 2000.

12. Nakagawa H, Kiyozuka Y, Uemura Y, Senzaki H, Shikata N, Hioki $\mathrm{K}$ and Tsubura A: Resveratrol inhibits human breast cancer cell growth and may mitigate the effect of linoleic acid, a potent breast cancer cell stimulator. J Cancer Res Clin Oncol 127: 258-264, 2001.

13. Soule HD, Vazguez J, Long A, Albert S and Brennan M: A human cell line from a pleural effusion derived from a breast carcinoma. J Natl Cancer Inst 51: 1409-1416, 1973.

14. Kurebayashi J, Kurosumi M and Sonoo H: A new human breast cancer cell line, KPL-1 secretes tumour-associated antigens and grows rapidly in female athymic nude mice. $\mathrm{Br} \mathrm{J}$ Cancer 71 : 845-853, 1995.

15. Cailleau R, Young R, Olive M and Reeves WJ Jr: Breast tumor cell lines from pleural effusions. J Natl Cancer Inst 53: 661-674, 1974.

16. Yuri T, Danbara N, Tsujita-Kyutoku M, Kiyozuka Y, Senzaki H, Shikata N, Kanzaki H and Tsubura A: Perillyl alcohol inhibits human breast cancer cell growth in vitro and in vivo. Breast Cancer Res Treat 84: 251-260, 2004.

17. Maggiolini M, Bonofiglio D, Marsico S, Panno ML, Cenni B, Picard D and Ando S: Estrogen receptor alpha mediates the proliferative but not the cytotoxic dose-dependent effects of two major phytoestrogens on human breast cancer cells. Mol Pharmacol 60: 595-602, 2001.

18. Ahamed S, Foster JS, Bukovsky A and Wimalasena J: Signal transduction through the Ras/Erk pathway is essential for the mycoestrogen zearalenone-induced cell-cycle progression in MCF-7 cells. Mol Carcinog 30: 88-98, 2001.

19. Withanage GS, Murata H, Koyama T and Ishiwata I: Agonistic and antagonistic effects of zearalenone, an etrogenic mycotoxin, on SKN, HHUA, and HepG2 human cancer cell lines. Vet Hum Toxicol 43: 6-10, 2001.

20. Sherr CJ: G1 phase progression: cycling on cue. Cell 79: 551-555, 1994.

21. Jacks T and Weinberg RA: Cell-cycle control and its watchman. Nature 381: 643-644, 1996.

22. Sherr CJ and Roberts JM: CDK inhibitors: positive and negative regulators of G1-phase progression. Genes Dev 13: 1501-1512, 1999.

23. Liu S and Lin YC: Transformation of MCF-10A human breast epithelial cells by zeranol and estradiol-17beta. Breast J 10: 514-521, 2004.

24. Cappelletti V, Fioravanti L, Miodini P and Di Fronzo G: Genistein blocks breast cancer cells in the $\mathrm{G}(2) \mathrm{M}$ phase of the cell cycle. J Cell Biochem 79: 594-600, 2000.

25. Matsukawa Y, Marui N, Sakai T, Satomi Y, Yoshida M, Matsumoto K, Nishino H and Aoike A: Genistein arrests cell cycle progression at G2-M. Cancer Res 53: 1328-1331, 1993.

26. Abid-Essefi S, Baudrimont I, Hassen W, Ouanes Z, Mobio TA, Anane R, Creppy EE and Bacha H: DNA fragmentation, apoptosis and cell cycle arrest induced by zearalenone in cultured DOK, Vero and Caco-2 cells: prevention by Vitamin E. Toxicology 192: 237-248, 2003. 
27. Peethambaram PP, Ingle JN, Suman VJ, Hartmann LC and Loprinzi CL: Randomized trial of diethylstilbestrol vs. tamoxifen in postmenopausal women with metastatic breast cancer. An updated analysis. Breast Cancer Res Treat 54: 117-122, 1999.

28. Vanzulli S, Efeyan A, Benavides F, Helguero LA, Peters G, Shen J, Conti CJ, Lanari C and Molinolo A: p21, p27 and p53 in estrogen and antiprogestin-induced tumor regression of experimental mouse mammary ductal carcinomas. Carcinogenesis 23: 749-758, 2002.
29. Brunner N, Spang-Thomsen M, Vindelov L and Nielsen A: Effect of 17 beta-oestradiol on growth curves and flow cytometric DNA distribution of two human breast carcinomas grown in nude mice. Br J Cancer 47: 641-647, 1983.

30. Liu H, Lee ES, Gajdos C, Pearce ST, Chen B, Osipo C, Loweth J, McKian K, De Los Reyes A, Wing L and Jordan VC: Apoptotic action of 17beta-estradiol in raloxifene-resistant MCF-7 cells in vitro and in vivo. J Natl Cancer Inst 95: 1586-1597, 2003.

31. Gomez-Lazaro M, Fernandez-Gomez FJ and Jordan J: p53: Twenty five years understanding the mechanism of genome protection. J Physiol Biochem 60: 287-307, 2004. 